\title{
REFLEXÕES ACADÊMICAS SOBRE O ESTUPRO MARITAL ATRAVÉS DA HISTORICIDADE DA VIOLÊNCIA SEXUAL E DE GÊNERO
}

\author{
Breno Rosostolato \\ ACADEMIC REFLECTIONS ABOUT MARITAL RAPE THROUGH THE HISTORICITY \\ OF SEXUAL VIOLENCE AND GENDER
}

\begin{abstract}
Resumo: Esta pesquisa busca a reflexão e o debate não apenas sobre a prática do estupro, mas contextualizando e problematizando-o à luz das relações conjugais. Em uma perspectiva histórica, as violências nas relações conjugais evidenciam a relação entre o marido e a esposa pela noção de propriedade, das relações de poder e, portanto, das violências de gênero. Conflitos invisibilizados pelo matrimônio. O olhar sobre o estupro conjugal busca revelar não apenas o crime de estupro, já tipificado, mas também o ato de dominação. O estudo debruça-se sobre o tema a fim de entender as especificidades da violência sexual no casamento e implicações aos envolvidos e à família. A revisão bibliográfica objetivou estudar o estupro como prática naturalizada na sociedade, considerando como cenário um sistema que reforça essas violências, o patriarcado: sistema que dispõe de instrumentos de controle, privilégios e que acentua o feminicídio. Um debate emergencial a fim de fomentar o diálogo para uma educação em sexualidade, a conscientização da prática sexual consentida, o combate ao sexismo e a não abjeção das mulheres. Este é o panorama que se espera diante da promoção ao respeito e dignidade nas relações conjugais.
\end{abstract}

Palavras-chave: estupro marital; violência de gênero; violência sexual; machismo; feminicídio

Abstract: This research aims to the reflection and debate not only about the practice of rape, but to contextualize it and take it into account concerning conjugal relations. Through a historical perspective, the violence in conjugal relations, evidences the idea of property between husband and wife, power dispute and, therefore, gender violence. Conflicts eclipsed by the institution of matrimony. This gaze over the conjugal rape seeks the revelation not only of the crime of rape, beforehand tipifyed, but also, the act of domination. This study unfolds over the theme in order to understand the specifications of sexual violence in the marriage and implications to the people involved and the family. The bibliographic review objectified the studying of rape as a practice naturalized within the society, considering a scenario that supports these violences, the patriarchate. Such system holds instruments of control, priviledges and the reinforcement of feminicide. An inpending, of uttermost urgency debate, brought up in order to encourage the dialogue into an education in sexuality, the awareness on conscented intercourse, the fight against sexism and the non abjection of wonen. This is the overview expected as a result through the promotion of respect and dignity in conjugal relations.

Palavras-chave: marital rape; gender violence; sexual violence; chauvinism; feminicide

\footnotetext{
Graduado em psicologia. Pós-graduado em Educação em Sexualidade e integrante do Grupo de Pesquisa em Sexualidade Humana do Centro Universitário Salesiano (UNISAL). Articulista em jornais, revistas e sites sobre temas voltados à sexo, sexualidade e gênero. E-mail: brenorosostolato@gmail.com.
} 


\section{Introdução}

As relações de poder e violência contra a mulher fazem parte da concepção do casamento, que consiste em objetificação, que, segundo Belmiro et al. (2015), consiste em considerar o indivíduo no patamar de objeto, sem considerar os aspectos emocionais ou psicológicos, tal como uma 'coisificação', no sentido de desumanizar a mulher em detrimento da posição hegemônica do homem. Processos históricos vividos pelas mulheres.

Dias e Silva (2008, p. 176) explicam sobre o mecanismo de coisificação que se caracteriza pela "retirada dos aspectos humanos das pessoas, [...] passando a transformá-lo, a seus olhos, em coisa". O agressor acredita, assim, anular qualquer ameaça a si mesmo.

Essas práticas misóginas tornam o corpo da mulher como um objeto de prazer, e por outro, esta mulher abjeta, rejeitando seus limites, desejos, vontades, direitos e a invisibiliza enquanto mulher, relegada a uma condição de vulnerabilidade e opressão constante. As relações são abusivas, nele o sexo é instrumento de poder, por isso é forçado e torna-se fonte de controle.

Segundo Mikolci (2015, p. 24), a abjeção se refere "ao espaço a que a coletividade costuma relegar aqueles e aquelas que considera uma ameaça ao seu bom funcionamento, à ordem social e política". A abjeção atua como forma de "invisibilizar" os novos formatos familiares, enquanto instituição, bem como os integrantes desta família. Para Júlia Kristeva (1988), a abjeção parte de dois momentos específicos da aquisição da linguagem no sujeito: semiótica e simbólica. Para a autora, abjeção é aquilo que se produz de forma ameaçadora e não assimilável; "O que nos torna abjeto é aquilo que perturba uma identidade, um sistema, uma ordem. Aquilo que não respeita os lugares, os limites, as regras". (KRISTEVA, 1988, Apud AVILA, 2014, p. 27-28).

As questões relacionadas ao estupro marital devem ser compreendidas por aspectos importantes e que precisam ser analisados minuciosamente para se entender as raízes desta violência.

É na busca por algumas respostas que este artigo parte da seguinte reflexão: Uma relação sexual não consentida em qualquer relacionamento pode ser considerada abuso, violência e até mesmo estupro. E nas relações conjugais, o sexo sem consentimento pode se caracterizar como um crime de estupro?

A resposta parece óbvia, tendo em vista que o não consentimento ao ato sexual já seria motivo suficiente para não acontecer uma relação sexual. Mas a naturalização da submissão e obediência das esposas ao marido muitas vezes oculta o crime que passa desapercebido ou é ignorado.

O estupro seria uma maneira de forçar a mulher ao ato sexual através da violência e, ao mesmo tempo, desumanizá-la enquanto mulher (TIBURI, 2015), uma inessencialidade, consequência da exclusão e do preconceito social e que não se restringiria à violência contra mulher (feminicídio), mas também à violência contra homossexuais (homofobia), assassinatos de travestis e transexuais (transfobia), racismo, morte de pobres e violências que resultariam na exclusão do outro.

Exclusão do subalterno, pessoas ou grupos que estão fora do poder, da estrutura hegemônica. Uma subalternidade que é lugar do silêncio (SPIVAK, 2010) e da invisibilidade. Daí a ideia de servidão no estupro marital, pois o inessencial deveria servir o essencial, a sujeição da esposa ao marido.

Esta relação de poder generificada (gendered $)^{2}$ estabelecida no casamento agirá como uma tecnologia política do corpo (FOUCAULT, 2015), estratégias de apropriação e consequentemente, de dominação, em que "não há relação de poder sem constituição correlata de um campo de saber" (FOUCAULT, 2014, p. 31). São esses saberes produzidos pelo patriarcado que é preciso compreender para desvelar a lógica do estupro.

\section{Metamorfoses patriarcais através do casamento}

O patriarcalismo seria um dispositivo (GODINHO, 1995) que não só produz saberes, como opera no sentido de doutrinar as pessoas, principalmente as mulheres. Este sistema era considerado como "governo dos patriarcas", como explica Garcia (2015), mas é a partir do século XIX que

\footnotetext{
${ }^{2}$ Gendered significa tanto generificado como, generificada. Adotarei a explicação de Connell (2016), em que ele explica a prática da língua, no caso inglês, que consiste em transformar substantivos em adjetivos. Para isto, a inclusão da desinência, ou seja, elementos terminais indicativos das flexões das palavras. No caso, a palavra gênero sofreu uma transformação e indica que uma pessoa, grupos, espaços, objetos, o casamento, alvo deste estudo, sofreu um processo e significações, consequência das dinâmicas de gênero. Assim, generificar, enquanto verbo resultou num desdobramento, o substantivo, generificação.
} 
surgem teorias que enfatizam a hegemonia masculina e, com isso, um sentido crítico do termo. É neste ínterim que trago a seguinte definição:

Forma de organização política, econômica, religiosa, social baseada na ideia de autoridade e liderança do homem, no qual se dá o predomínio dos homens sobre as mulheres; do marido sobre as esposas, do pai sobre a mãe, dos velhos sobre os jovens, e da linhagem paterna sobre a materna. O patriarcado surgiu da tomada de poder histórico por parte dos homens que se apropriaram da sexualidade e reprodução das mulheres e seus produtos: os filhos, criando ao mesmo tempo uma ordem simbólica por meio dos mitos e da religião que o perpetuam como única estrutura possível. (REGUANT, apud GARCIA, 2015, p. 17)

Desde o período Neolítico e as sociedades agrícola e pastoril, como nos situa historicamente Lins (2007), o homem compreende sua função social e apropria-se do poder da fecundação, atribuindo ao sêmen o dom da vida.

A paternidade passa a ser a principal via de controle sobre as mulheres, pois a sociedade passa a valorizar o falo, símbolo que passa a representar a fecundidade, em que "a filiação passou a ser masculina, a herança também [...], o homem apoderou-se da direção da casa". (LINS, 2007, p. 28)

Consequência disso é a desvalorização da mulher e a hegemonia masculina. A fertilidade, que era a consagração à vida, passa a ser associada, portanto, ao homem. Esse falocentrismo no qual, a apropriação da paternidade e o primor da vida fez com que o homem passe a comandar sua vida pautada nesse poder e na concepção. Essa configuração marca profundamente uma divisão social entre o casal para o surgimento do sistema patriarcal.

O sexo passa a ser uma prática e um instrumento de divisão social que define pontualmente o poder daqueles que comandam e a submissão e subalternidade dos que são comandados.

$\mathrm{O}$ ato sexual é, portanto, um ato de dominação e consagração do homem. A relação sexual é um forte artifício para a constituição do patriarcado e a binaridade de gênero, divisão complexa e enraizada na sociedade que estabelece categorias que são hierarquizadas. Assim, uma categoria das mulheres (BUTLER, 2015) estaria a serviço das normas patriarcais e, portanto, excluída dos privilégios da categoria homem.

Binaridade define homens e mulheres e torna as relações amorosas condicionadas a essa dualidade. A paternidade cria no homem outro sentimento e que será determinante para a construção das sociedades patriarcais, o de exclusividade e importância exacerbada (LINS, 2007), no que se refere à criação do filho e também da muIher.

A religião vai aos poucos reforçando a soberania masculina, haja vista a história da criação do homem e da mulher. Deus é referendado como um ser masculino, o Pai, que cria o homem, Adão, que, diga-se de passagem, criado à imagem e semelhança do Criador. Deste homem retira-se a costela para assim surgir a mulher, Eva.

Esse novo sistema traz consigo uma consequência clara de divisão da sociedade. Uma organização social pautada no poder do pai, na qual a mulher deveria sentir-se agradecida por ter recebido do homem a dádiva da vida. Sentimento esse que cria também dependência, submissão e inferioridade ao homem. Sendo assim, não se deve contestar as ordens e diretrizes impostas pelos homens. A obediência passa a ser a principal virtude das mulheres. O patriarcado transforma-se de uma hierarquização social para um sistema político (GARCIA, 2015).

Formulam-se assim algumas mentalidades importantes e contundentes sobre o casamento, tomando como perspectiva a dominação dos homens sobre as mulheres e que serão determinantes para as definições de masculinidades e feminilidades. Marco da divisão sexual do trabalho e uma corporificação (embodiment), no sentido de os corpos serem usados para absorver normas e práticas sociais (CONNELL, 2016), estabelecendo diferenças no corpo enquanto um corpo feminino e outro "não feminino" (BOURDIEU, 2016).

No casamento, a concepção de renúncia e sacrifício (CHABONNEAU, 1985) era a tônica da relação estabelecida entre o casal. O casamento era celebrado através da Santa Eucaristia e lapidado em conceitos que, na Idade Média eram considerados sagrados e indiscutíveis, se consolidando como uma instituição por três pilares: oposição aos conceitos pagãos (FRANGIOTTI, 2006) e, consequentemente, conforme Lins (2012), seu enfraquecimento, a obediência divina e, por fim, interesses materiais e políticos.

Conforme afirma Westermark (1891, apud RUSSELL, 2015, p. 33) o casamento "tem origem na família, não é a família que tem origem no casamento". Uma concepção que acrescenta um 
valor indubitável ao matrimônio e baseado na ética cristã.

A concepção de indissolubilidade do casamento, em que se reforça a ideia do permanente vínculo entre a esposa e o marido, além do incentivo à monogamia como única forma de relação conjugal, foi uma maneira de controle e efeito estabilizador (RICHARDS, 1993) a esse casal para uma formação social e androcêntrica. $O$ amor não era cogitado, no máximo poderia ser manifestado em casa de forma superficial e sem muitos envolvimentos íntimos.

O intuito primordial da união conjugal era procriar, deixar herdeiros, ou seja, assegurar os bens da família e, principalmente, serventia religiosa, ou seja, a prevenção do pecado.

Os homens assumem o protagonismo de decidir quando e porque ter filhos. A paternidade assegura ao homem sua transcendência através dos filhos, desde que, legítimos, pois como aponta Russell (2015, p. 18), "o filho legítimo é uma continuação do ego do homem, e sua afeição pelo filho é uma forma de egoísmo". Portanto, o filho ilegítimo coloca em questionamento o casamento, a paternidade e lógico, a soberania do homem sobre a mulher, afinal, ele foi traído. Daí que o controle das esposas era necessário para garantir os privilégios patriarcais e leis de propriedade e herança.

Este e o sistema que escravizou mulheres num ciclo contínuo de violência e que começa a ser rompido somente a partir da Revolução Industrial, originando a um novo e outro tipo de família, entretanto, as violências de gênero persiste, pois, são heranças patriarcais. Mulheres são, em muitas relações, colonizadas por companheiros a realizarem as vontades deles em detrimento da insatisfação e sofrimento delas.

\section{Ideologia e violência}

Em uma proposta de compreender os sistemas de gêneros e suas performatividades normativas (BUTLER, 2015), é importante desconstruirmos os conceitos que foram engessados na sociedade numa perspectiva histórica, e, a partir disso, redefinir os contratos sociais. (PRECIADO, 2014). Contratos que se não revistos, sustentarão as violências produzidas pelos equívocos das concepções de gêneros.

Comecemos com uma definição de Garcia para explorar melhor este conceito. Afirma a autora:
Conceito construído pelas ciências sociais nas últimas décadas para analisar a construção sócio-histórica das identidades masculina e feminina, [...] discursos de legitimação sexual ou ideologia sexual. Esses discursos legitimam a ordem estabelecida, justificam a hierarquização dos homens e do masculino e das mulheres e do feminino em cada sociedade determinada. São sistemas de crenças que especificam o que é característico de um e outro sexo e, a partir daí, determina os direitos, os espaços, as atividades e as condutas próprias de cada sexo. [...] Por gênero entendem-se todas as normas, obrigações, comportamentos, pensamentos, capacidades e até mesmo o caráter que se exigiu que mulheres tivessem por serem biologicamente mulheres. (GARCIA, 2015, p. 19)

A universalidade (BENTO, 2014) dos gêneros atribui aos sujeitos características determinadas, logo, compartilhadas por todos. Essa universalidade, em si, já é uma violência, pois reproduz uma ditadura de como ser e não contemplam a subjetividade e a singularidade das pessoas.

As atribuições das características dos gêneros que se aplicaria à todos, já é em si, uma violência, pois de fato, soam como uma violência contra as identidades

Berenice Bento alerta para uma "essencialização" do gênero ao citar, criticamente, Beauvoir. Eis sua interpretação:

O homem, para Beauvoir, representa o sujeito universal; e a mulher, por sua vez, seria o seu outro absoluto. Dessa forma, elas são mulheres em virtude de sua estrutura fisiológica; por mais que se remonte na história, sempre estiveram subordinadas ao homem. (BENTO, 2014, p. 84)

Essas identidades formuladas a partir do gênero aprisionam homens e mulheres a uma ordem totalitária e agressiva. Identidades que se constituem sem partir do unitário, mas de normas universais, como se esses conceitos se aplicassem obrigatoriamente a todos.

Essa identidade não seria o resultado de características pessoais, mas sofreria interferência de práticas reguladoras de formação e divisão de gênero. As leis que regem os gêneros antecederiam a formação de uma singularidade e da identidade da pessoa.

Uma ideologia que se resume na confluência de, por exemplo, um homem por sua ana- 
tomia masculina (corpo), deve ser masculino, e aqui, não há margem de discussão, ele deve não só desejar mulheres como ter relações sexuais com elas, ou seja, penetrando, afinal, sua genitália está ali para isso.

Pensar nas violências que as mulheres sofrem é compreender a violência transferida ao gênero feminino, que não é a mesma vivida pelo gênero masculino. Mais do que isso, diferenciar o termo gênero diante de um contexto patriarcal, pois o gênero antecede o patriarcado, e este intensificou a violência das normatizações, incidindo na mulher uma subalternidade e no homem uma obrigatoriedade de serem o que não são.

A violência praticada contra as mulheres, e especificamente o estupro marital, é também, uma maneira de alguns homens provarem algo para si mesmo. Uma prova que é mantida pela necessidade de responder às exigências do patriarcado e à primazia dos gêneros.

Não existe uma ideologia de gênero, esta uma desonestidade intelectual e com o propósito de invisibilizar e silenciar diferenças e ocultar desigualdades. O gênero é uma ideia dominante (CHAUÍ, 1999) transmitida através dos costumes, hábitos e dos saberes médicos, psicológicos, do direito, entre outros. Tudo isso com o intuito de moldar consciências e uniformizar as classes sociais.

\section{Confrontações e estatísticas}

As tentativas de confrontar as violências sexuais são e devem ser constantes. Em 2014 a campanha \#eunãomereçoserestuprada3 foi idealizada pela jornalista Nana Queiroz e em pouco tempo tornou-se uma coqueluche na internet. Foi criada para protestar contra a culpabilização da mulher em atos de violência sexual.

Outra campanha realizada em 2013 de grande repercussão é a "Chega de fiu fiu", contra o assédio sexual, na qual 7762 mulheres participaram de uma pesquisa e da quais $99,6 \%$ afirmaram que já foram assediadas. Conforme o site da campanha, $48 \%$ dos assédios sexuais são verbais, sendo que desses, $68 \%$ acontecem durante o dia. No link4 pode-se conferir depoimentos e o mapeamento do assédio sexual no Brasil.

Essas campanhas suscitam a reflexão e o debate sobre a violência sofrida pelas mulheres. Uma luta árdua e que não podem silenciar, pois, as mentalidades e posicionamentos generificados ainda persistem em nossa sociedade.

Conforme dados do relatório elaborado pelo Instituto Avante Brasil sobre Homicídios de mulheres no Brasil em 2013, 35\% das mulheres no mundo já sofreram violência física e/ou sexual por parceiro íntimo ou violência sexual por um não parceiro. A propósito, $70 \%$ das mulheres já experimentaram violência física e/ou sexual perpetrada por um parceiro íntimo. Números alarmantes.

Em recente pesquisa realizada pelo Fórum Brasileiro de Segurança Pública , 42\% dos homens entrevistados concordam com a afirmação "mulheres que se dão ao respeito não são estupradas", ou seja, a culpada do estupro recai sobre a vítima. Ainda sobre a pesquisa, em relatório intitulado \#APolíciaPrecisaFalarSobreEstupro, 65\% das mulheres entrevistadas afirmam ter medo de sofrer violência sexual, diante de $46 \%$ dos homens.

No ano de 2016, a ONU Mulheres publicou Diretrizes nacionais para investigar, processar e julgar com perspectiva de gênero as mortes violentas de mulheres - Feminicídios, em que são feitas recomendações para a revisão dos procedimentos de perícia, polícia, saúde e justiça que lidam com ocorrências de feminicídio. Essa é a realidade da violência contra as mulheres, que coloca o Brasil no alarmante quinto lugar da lista de países com os maiores índices de assassinatos de mulheres, 4,8 para 100 mil mulheres. Isso tudo mesmo diante da uma lei robusta como a Lei Maria da Penha.

A Lei Maria da Penha, n. 11.340, entrou em vigor no dia 22 de setembro de 2006. O nome em homenagem à Maria da Penha Maia, nascida no Ceará, biofarmacêutica e que lutou durante 20 anos para que a justiça condenasse seu agressor e marido, Marco Antonio Heredia.

Após ser agredida a primeira vez, Maria da Penha tornou-se paraplégica, depois que o marido desferiu-lhe um tiro. Na segunda tentativa de homicídio, Marco Antonio tentou eletrocutá-la.

Na época, 1983, a falta de uma legislação específica fez com que Maria da Penha ficasse desamparada, acentuando ainda mais seu estado de vulnerabilidade. Foi somente 8 anos após os fatos que Heredia foi condenado a oito anos de prisão, isso porque o caso chegou à Comissão Interamericana dos Direitos Humanos da Organização dos Estados Americanos (OEA).

Diante do apelo de órgãos internacionais e a repercussão do caso de violência doméstica, foi determinado ao Brasil o cumprimento dos tratados e leis vigentes para combater esse tipo de violência. 
O país percebeu a urgência de criar uma legislação que não só amparasse casos como o de Maria da Penha, mas que de fato deveria encarar essas violências sob caráter emergencial e de grande agravante social. O Brasil é o $18^{\circ}$ país a contar com um dispositivo jurídico para casos de violência doméstica e familiar contra a mulher.

A propósito de leis

Até a formulação da Lei 12.015/2009, publicada em 07 de agosto de 2009, muito se debateu sobre as questões dos crimes sexuais, o estupro, estupro marital e liberdade sexual. Debates que fomentaram inúmeras mudanças na legislação. $A$ redação final do Art. 213 define o crime de estupro como:

Constranger alguém, mediante violência ou grave ameaça, a ter conjunção carnal ou a praticar ou permitir que com ele se pratique outro ato libidinoso:

Pena - reclusão, de 6 (seis) a 10 (dez) anos.

§ 10 Se da conduta resulta lesão corporal de natureza grave ou se a vítima é menor de 18 (dezoito) ou maior de 14 (catorze) anos:

Pena - reclusão, de 8 (oito) a 12 (doze) anos.

$\S 20$ Se da conduta resulta morte:

Pena - reclusão, de 12 (doze) a 30

(trinta) anos.

Quanto ao estupro marital, foi em 2005 que se considerou o cônjuge ou companheiro da vítima como agente do crime de estupro, previsto no artigo 226 do Código Penal:

A previsão do cônjuge e do companheiro [...] é significativa, não pelo aumento da pena cominada ao crime sexual eventualmente praticado. Mas, pelo fato de espancar, de uma vez por todas, o entendimento recorrente de não caracterizar estupro a violência sexual praticada pelo marido contra a esposa. [...] Se a pena dos crimes sexuais é aumentada no caso de o agente se tratar de cônjuge da vítima, obviamente não cabe mais cogitar a não caracterização do estupro quando praticado no âmbito do matrimônio. (PASCHOAL, 2014, p. 70-71)

A Lei 13.104, 9 de março de 2015, alterou o Código Penal em seu artigo 121 do Decreto-Lei n. 2.848, de 7 de dezembro de 1940 e passa a prever o feminicídio como crime de homicídio clas- sificado contra a mulher por razões da condição de sexo feminino. O § 2o-A define duas razões para essa condição, violência doméstica e familiar e menosprezo ou discriminação à condição de mulher. Esse crime considerado hediondo.

\section{Considerações finais}

O casamento e os casos de estupro marital necessitam de um amplo debate na sociedade. Discussões que devem ter um caráter educacional, a fim de demonstrar que a crise do masculino é concomitante e consequência de mentalidades cada vez menos falocêntricas.

Quanto às mulheres, compreender sobre a violência sofrida na relação matrimonial é importante, pois, como sugere a psicanalista Marie-France Hirigoyen, reconhecer os primeiros sinais de violência, seja esta verbal, física ou simbólica, é necessário para que ela não seja envolvida num ciclo de agressões, medos e angústias. Até que ponto as mulheres casadas sabem identificar o abuso, a agressão sexual e distinguir o estupro marital?

O consentimento e o respeito ao limite do outro, inclusive, no contexto do casamento, deve ser comum e, natural. As relações conjugais não admitem mais os retrógrados conceitos de imposição e arbitrariedades machistas e misóginas. O momento histórico e cultural, as questões de direitos emancipatórios, leis específicas que visam proteger a integridade das mulheres e principalmente, o empoderamento delas nos vários setores, segmentos e faixa etária, demonstram as metamorfoses do feminino.

As questões relacionadas ao estupro marital precisam ser refletidas e é chegado o momento que a sociedade não pode ignorar esta realidade. A recusa da esposa em ter relações sexuais com o marido, não o autoriza a estupra-la, ou seja, violentar seu corpo e sua dignidade.

A comprovação do estupro conjugal é difícil de identificar, pois sua prática se mantém pelo silenciamento da vítima e, sobretudo, pelo débito (PRIORI, 2011) matrimonial. Por isso a importância de uma educação e orientação às mulheres, no sentido de fortalecê-las, a ponto de não mais se calarem e saber sair de relações violentas, assim como, uma reeducação em sexualidade aos maridos para reconhecerem posicionamentos opressores e agressivos. Por uma reeducação que possa favorecer à desconstrução do machismo por parte deles também.

Que os casamentos não se constituam atra- 
vés de sofrimentos e não sejam frutos de sacrifícios. Que as relações conjugais não invisibilizem o outro. Que prazeres e desejos não se baseiem em coerções e constrangimentos e que não sucumbam o prazer do outro. Que a palavra consentimento prevaleça em seu significado pleno.

Por fim, este artigo sugere que outras pesquisas e estudos aconteçam sobre o tema e que, desta maneira, a literatura instigue o debate na sociedade. Somente desta maneira conseguiremos contribuir para mudar o triste cenário de violência contra as mulheres e as questões envolvidas ao estupro marital.

\section{Referências}

ANUÁRIO BRASILEIRO DE SEGURANÇA PÚBLICA - 2015. Fórum Brasileiro de Segurança Pública on-line, São Paulo, ano 9, 2015. Disponível em: $<$ http://www.forumseguranca.org.br/>. Acesso em: 03 mar. 2017.

ÁVILA, Simone. Transmasculinidades: A emergência de novas identidades políticas e sociais. Rio de Janeiro: Multifoco, 2014.

BOTELHO, Flávia Mestriner. Homicídios de muIheres no Brasil em 2013. Instituto Avante Brasil. Disponivel em: <http://d2kefwu52uvymq.cloudfront.net/uploads/2015/10/Levantamento-genero.pdf>. Acesso em 04 mar. 2017.

BOURDIEU, Pierre. A dominação masculina. trad. Maria Helena Kuhner. 3 ed. Rio de Janeiro: BestBolso, 2016.

BRASIL. Art. 226. Código Penal.

BRASIL. decreto-lei No 28487 de dezembro de 1940.

BRASIL. Lei Maria da Penha, n. 11.340, 22 de setembro de 2006.

BRASIL. Lei n. 12.015, 7 de agosto de 2009.

BRASIL. Lei n. 13.104, 9 de março de 2015.

BUTLER, Judith. Problemas de Gênero: feminismo e subversão da identidade. Trad. Renato Aguiar. 8 ed., Rio de Janeiro: Civilização Brasileira, 2015.

BELMIRO, Dalila Maria Musa et al. Empoderamento ou Objetificação: Um estudo da imagem fe- minina construída pelas campanhas publicitárias das marcas de cerveja Devassa e Itaipava. XXXVIII Congresso Brasileiro de Ciências da Comunicação, Rio de Janeiro, 2015. Disponível em: < http://portalintercom.org.br/anais/nacional2015/resumos/ R10-1863-1.pdf>. Acesso em: 04 mar. 2017.

CONNELL, Raewyn. Gênero em termos reais. Trad. Marília Moschkovich. São Paulo: nVersos, 2016.

CHARBONNEAU, Paul Eugène. Sentido cristão do casamento: ensaio a respeito da espiritualidade conjugal. 2 ed. São Paulo: Loyola, 1985.

CHAUÍ, Marilena de Souza. Convite à filosofia. 12 ed. São Paulo: Ática, 1999.

DIAS, Victor R. C. S; SILVA, Virgínia de Araújo. Psicopatologia e psicodinâmica na análise psicodramática. São Paulo: Ágora, 2008. 2. v.

ONU MULHERES. Diretrizes Nacionais Feminicídio: investigar, processar e julgar com perspectiva de gênero as mortes violentas de mulheres. Brasília: ONU, Abril 2015. Disponível em: <http:// www.onumulheres.org.br/wp-content/uploads/2016/04/diretrizes_feminicidio.pdf >. Acesso em 04 mar. 2017.

FOUCAULT, Michel. Vigiar e Punir: nascimento da prisão. Trad. Raquel Ramalhete. 42 ed. Petrópolis: Vozes, 2014.

FOUCAULT, Michel. Microfísica do poder. Organização, introdução e revisão téc. Roberto Machado. 2 ed. Rio de Janeiro: Paz e Terra, 2015.

FRANGIOTTI, Roque. Cristãos, judeus, pagãos: acusações, críticas e conflitos no cristianismo antigo. Aparecida: Ideias \& Letras, 2006.

GARCIA, Carla Cristina. Breve história do feminismo. São Paulo: Claridade, 2015.

GODINHO, Eunice Maria. Educação e disciplina. Rio de Janeiro: Diadorim, 1995.

MISKOLCl, Richard. Teoria Queer: um aprendizado pelas diferenças. 2 ed. Rev. e ampl., 2 reimp. Belo Horizonte: Autêntica, UFOP - Universidade Federal de Ouro Preto, 2015.

PASCHOAL, Nohara. O estupro: uma perspectiva vitimológica, Rio de Janeiro: Lumen Juris, 2014. 
PRECIADO. Beatriz. Manifesto Contrassexual. Trad. Maria Paula Gurgel Ribeiro. São Paulo: n-1 edições, 2014.

PRIORE, Mary Del. Histórias Íntimas: sexualidade e erotismo na história do Brasil. São Paulo: Planeta do Brasil, 2011.

QUEIROZ, Nana. Ponto de vista: Revolta contra estupro coletivo ainda fecha os olhos para violência sexual mais comum no Brasil. BBC Brasil, 27 maio 2016. Disponível em: <http://www.bbc. com/portuguese/brasil-36401058>. Acesso em: 04 mar. 2017.

RICHARDS, Jeffrey. Sexo, desvio e danação: as minorias na Idade Média. Trad. Marco Antonio Esteves da Rocha e Renato Aguiar, Rio de Janeiro: Jorge Zahar, 1993.

RUSSELL, Bertrand. Casamento e moral. Trad. Fernando Santos. São Paulo: Unesp, 2015.

SPIVAK, Gayatri Chakravorty. Pode o subalterno falar? Trad. Sandra R. Goulart Almeida; Marcos Feitosa; André Feitosa. Belo Horizonte: UFMG, 2010.

SITE THINK OLGA. Chega de Fiu Fiu: Resultado da pesquisa. Think Olga, 09 set. 2013. Disponível em: <http://thinkolga.com/2013/09/09/chega-de-fiu-fiu-resultado-da-pesquisa/>. Acesso em: 03 mar. 2017.

TIBURI, Márcia. Democracia Hard: homens, feminismo e machismo ao contrário. Revista Cult, 10 jun. 2015. Disponível em: < http://revistacult. uol.com.br/home/2015/06/democracia-hard-homens-feminismo-e-machismo-ao-contrario/>. Acesso em 03 mar. 2017. 